\title{
Short communication: Genetic evaluation of stillbirth in US Brown Swiss and Jersey cattle
}

\author{
C. Yao, ${ }^{*}$ K. A. Weigel, ${ }^{*}$ and J. B. Cole ${ }^{1}$ \\ *Department of Dairy Science, University of Wisconsin, Madison 53706 \\ †Animal Improvement Programs Laboratory, Agricultural Research Service, US Department of Agriculture (USDA), Beltsville, MD 20705-2350
}

\begin{abstract}
Stillbirth (SB) often results in reduced milk yield, compromised reproductive performance, and decreased dam longevity. Corrective mating can be used as a shortterm solution to the problem, but long-term improvement of the population requires the routine calculation of genetic evaluations. Breeding values for SB have been available for Holstein (HO) bulls since 2006, but not for Brown Swiss (BS) or Jersey (JE) bulls. In this study, a multi-breed sire-maternal grandsire threshold model was used to perform genetic evaluations for SB of BS, $\mathrm{JE}$, and HO bulls using more than 14 million purebred and crossbred calving records. Phenotypically, the percentage of SB (\%SB) across all lactations were $3.7 \%$ in JE, $5.1 \%$ in BS, and $6.3 \%$ in HO. Direct heritabilities for BS, JE, and $\mathrm{HO}$ were $0.008,0.007$, and 0.008 , and maternal heritabilities were $0.002,0.016$, and 0.021 , respectively. Compared with $\mathrm{HO}$, crossbred calvings from BS and JE bulls bred to HO cows lowered \% SB by 1.5 and $1.2 \%$, respectively. In general, \% SB increased considerably as calving difficulty increased in all 3 breeds; however, in JE, \%SB was constant for dystocia scores of 3 (needed assistance), 4 (considerable force), and 5 (extreme difficulty). Compared with purebred HO calvings, purebred BS and JE calvings had lower phenotypic \% SB by up to 5.5 and $7.8 \%$, respectively, and $\mathrm{BS} \times \mathrm{HO}$ and $\mathrm{JE} \times \mathrm{HO}$ crossbred calvings decreased \%SB by up to 3.8 and $4.1 \%$, respectively. As expected, $\mathrm{SB}$ rates in primiparous cows were higher than those in multiparous cows. Female calves had greater \%SB than male calves in all parities for JE and in second-andlater parities for BS. Favorable (decreasing) phenotypic and genetic trends from 1999 to 2009 were observed in all 3 breeds. Heterosis of SB for BS and JE was -0.026 and -0.149 , respectively, on the underlying scale, which corresponds to effects on service-sire SB (SSB) and daughter SB (DSB) predicted transmitting ability (PTA) of -0.3 and $-0.5 \%$ in BS, and -1.5 and
\end{abstract}

Received July 30, 2013.

Accepted December 4, 2013.

${ }^{1}$ Corresponding author: john.cole@ars.usda.gov
$-2.7 \%$ in JE. Overall, in the current population, BS bulls had the most desirable average SSB PTA of $4.8 \%$, compared with $5.6 \%$ for JE and $5.5 \%$ for HO. Brown Swiss and JE bulls both had average DSB PTA of 6.5\%, lower than that of $7.7 \%$ in HO. Average reliabilities of $\mathrm{SSB}$ and DSB in 3 breeds ranged from 45 to $50 \%$. The use of a BS-JE-HO multibreed genetic evaluation for SB in the United States is feasible, and the addition of SSB and DSB to the lifetime net merit selection index will help improve the profitability of BS and JE cattle in the United States.

Key words: genetic evaluation, stillbirth, Brown Swiss, Jersey

\section{Short Communication}

Stillbirth (SB) often results in reduced milk yield, compromised reproductive performance, and decreased longevity of dams (Berry et al., 2007; Bicalho et al., 2007, 2008), and replacing stillborn calves also costs dairy producers substantially each year (Meyer et al., 2001a). Due to the different direct and maternal genetic correlations between SB and calving ease (CE) reported, Johanson et al. (2011) recommended evaluating for SB and CE separately. For Holsteins (HO) in the United States, genetic evaluations for CE have been available since 1978 (Berger, 1994; Van Tassell et al., 2003), and SB evaluations were first published in 2006 (Cole et al., 2007a). The calving ability index, including economic values of both SB and CE, was added into the 2006 revision of lifetime net merit, the selection index recommended for ranking US dairy cattle, to obtain continuous genetic improvement (Cole et al., 2009). However, SB evaluations have not previously been available for US Brown Swiss (BS) and Jersey (JE) cattle due to insufficient data (Cole et al., 2007a). The objectives of the current study were (1) to characterize SB data for US BS and JE and (2) to implement a multibreed sire-maternal grandsire (S-MGS) threshold model for SB including US BS, JE, and HO.

In the United States, SB is defined to include those calves born dead and those dying within $48 \mathrm{~h}$ of birth (Cole et al., 2007a). Stillbirth records ( $\mathrm{n}=24,311,207)$ from single births in $\mathrm{BS}$, JE, and $\mathrm{HO}$ cattle were 
extracted from the national dairy database (Animal Improvement Programs Laboratory, Agricultural Research Service, US Department of Agriculture, Beltsville, MD), and subjected to a series of data quality edits modeled after Van Tassell et al. (2003). Data included purebred calvings from all 3 breeds, as well as $\mathrm{BS} \times \mathrm{HO}$ and $\mathrm{JE} \times \mathrm{HO}$ first-generation $\left(\mathrm{F}_{1}\right)$ crossbred calves, which was similar to the multibreed model used for CE in the United States (Cole et al., 2005). Calf livability was reported on a 3 -point scale, where 1,2 , and 3 represented calves born alive, calves born dead, and calves that died within $48 \mathrm{~h}$ postpartum, respectively. Records with no livability scores were excluded from the analysis, and scores of 2 and 3 were combined to produce a 2-point scale. To avoid bias from herds that reported only live calves, herds were required to report at least $5 \mathrm{SB}$ to be included in the analysis. At least 1,000 records were required for an individual sire or MGS birth year to be included in the analysis to avoid biased sire birth-year or MGS birth-year group solutions (defined in model 1 below) due to insufficient data. After editing, 14,364,811 SB records were available for analysis. Figure 1 shows distributions of the number of records by dam birth year for BS and JE. The SB data set is a subset of the CE data set, and the complete CE pedigree file $(\mathrm{n}=176,683$ bulls $)$ was used for the SB analysis.

A multibreed S-MGS threshold model was used to estimate (co)variance components and compute PTA for SB using the THRGIBBS1F90 version 2.56 (Misztal et al., 2002) and CBLUP90IOD version 2.33 (Misztal et al., 2002) packages, respectively:

$\mathrm{y}=\mathrm{HY}+\mathrm{YS}+\mathrm{PS}+\mathrm{Br}+\mathrm{Y}_{\mathrm{s}}+\mathrm{Y}_{\mathrm{m}}+\mathrm{s}+\mathrm{m}+\mathrm{e}$,

where $\mathrm{y}$ is the SB score, $\mathrm{HY} \sim N\left(0, \mathbf{I} \sigma_{H Y}^{2}\right)$ is the random herd-year effect, YS is the fixed year-season effect, PS is the fixed parity-sex combination effect, $\mathrm{Br}$ is the fixed breed composition effect, $\mathrm{Y}_{\mathrm{s}}$ is the fixed sire birthyear effect, $Y_{m}$ is the fixed MGS birth-year effect, $\mathrm{s} \sim N\left(0, \mathbf{A} \sigma_{s}^{2}\right)$ is the random sire effect, $\mathrm{m} \sim N\left(0, \mathbf{A} \sigma_{m}^{2}\right)$ is the random MGS effect, and e $\sim N\left(0, \mathbf{I} \sigma_{e}^{2}\right)$ is the random error, where $\mathbf{A}$ is a pedigree-based additive relationship matrix, $\mathbf{I}$ is an identity matrix, and $\sigma_{H Y}^{2}, \sigma_{s}^{2}$, $\sigma_{m}^{2}$, and $\sigma_{e}^{2}$ are variances of the herd-year, sire additive genetic, MGS additive genetic, and random error effects, respectively.

The levels of fixed effects in the model were defined as follows: year-season groups began in October and May across year boundaries, and parities were first, second, and third or later. Breed composition of calves included
HO purebred calvings, BS purebred calvings, BS $\times$ HO crossbred calvings, JE purebred calvings, and JE $\times \mathrm{HO}$ crossbred calvings. Sire birth-year groups were defined as $\leq 1981,1982$ to 1983,1984 to $1985,1986,1987, \ldots$, 2007 , and $\geq 2008$. Maternal grandsire birth-year groups were different for animals with known and unknown MGS identification (ID). For animals with known MGS ID, groups were $\leq 1981,1982$ to 1983,1984 to $1985,1986,1987, \ldots, 2005$, and $\geq 2006$; for animals without valid MGS ID, groups were $\leq 1981,1982$ to 1983,1984 to $1985,1986,1987, \ldots, 2007$, and $\geq 2008$. These were assigned based on dam birth year, which was approximated as calving year - parity -1 .

Priors were those reported in Cole et al. (2007b): herd-year: 0.08; sire: 0.008; MGS: 0.018; S-MGS: 0.004; and residual: 1.000. These parameters were used in both the multibreed PTA prediction and (co)variance component estimation in each breed of BS, JE, and HO. To estimate genetic (co)variance components, 1 Gibbs chain of 50,000 samples was drawn, the first 10,000 samples were discarded as burn-in, and every fifth sample from the remaining 40,000 samples was included in the summary. No trend was observed in plots of Gibbs samples for each of the random effects; therefore, a longer burn-in period or a longer chain was not necessary. Heritabilities and correlations were


Figure 1. The number of stillbirth records by dam birth year in first (black), second (gray), and third-or-later parities (white) for (a) Brown Swiss purebred and crossbred calvings and (b) Jersey purebred and crossbred calvings. 
calculated using the average posterior means from the 8,000 samples being used, similarly to as done in the study of Cole et al. (2007b). For the PTA prediction, iteration was continued until convergence was achieved, which occurred in round 40.

Postprocessing of threshold model results followed a similar procedure as that used for the routine US SB evaluations as described by Cole et al. (2005, 2007a). On the underlying scale, the sire birth-year group solution was added to the sire solution; the MGS birth-year group solution and the breed composition solution of the MGS were added to the MGS solution. The sire and MGS solutions were then transformed to the observed scale and named service-sire SB (SSB) and daughter SB (DSB). Genetic bases for SSB and DSB for each breed were defined by the average percentage of SB $(\% \mathrm{SB})$ of cows with sires or grandsires born between 2001 to 2005 and between 1996 to 2000, respectively. Phenotypic bases of SSB and DSB for each breed were set to be average \% SB of bulls born from 2001 to 2005 and 1996 to 2000, respectively. A multiple-year average was used to smooth large year-to-year variation due to limited data and variation in the number of calvings in individual years.

Reliabilities were determined using the inverse of diagonal information:

$$
r e l_{i, t}=1-\frac{d i a g_{i, t}^{-1}}{\sigma_{t}^{2}}
$$

where $r e l_{i, t}$ is the reliability of sire $i$ for trait $t$ (sire or MGS effect), diag $_{i, t}$ is the diagonal element from the threshold model equations, and $\sigma_{t}^{2}$ is the genetic variance of trait $t$.

Data were summarized using the SAS System for Linux (version 9.3; SAS Institute Inc., Cary, NC), and R 3.0.0 (R Core Team, 2013). Figures were drawn in $\mathrm{R}$ using the "lattice" package version 0.20-15 (Sarkar, 2008). Calculations were performed on an IBM xSeries 3850 server (IBM Corp., Armonk, NY) running Red Hat Enterprise Linux 5.0 (Red Hat Inc., Raleigh, NC).

For BS, JE, and $\mathrm{HO}$, direct heritabilities were 0.008, 0.007 , and 0.008 , respectively, and maternal heritabilities were $0.002,0.016$, and 0.021 , respectively. Estimates of $\mathrm{HO}$ were intermediate to previous results, ranging from below 0.01 to 0.05 (Steinbock et al., 2003; Cole et al., 2007b; Johanson et al., 2011; Eaglen et al., 2012). Brown Swiss results were slightly lower than those of Fuerst and Egger-Danner (2003), who reported direct and maternal heritabilities of 0.02 for first calvings and 0.01 for later calvings. Jakobsen and Fikse (2005) summarized that heritabilities of direct (maternal) SB ranged from 0.015 to 0.03 (0.015 to
$0.05)$ between countries for BS, and 0.03 to $0.05(0.02$ to 0.05 ) for JE. Based on these results, BS and JE had similar estimated heritabilities as HO for SB. It is reasonable to combine data from all 3 breeds into a multibreed BS-JE-HO evaluation, and the numbers of BS and JE records were sufficient to provide informative joint evaluation with $\mathrm{HO}$.

Distributions of $\mathrm{SB}$ and $\mathrm{CE}$ scores in $\mathrm{BS}, \mathrm{JE}$, and $\mathrm{HO}$ are shown in Figure 2. In general, the percentage of stillborn calves increases considerably as calving difficulty increases, from less than $4 \%$ for all breeds in the case of no difficulty (CE score =1) to $44.3 \%$ in $\mathrm{HO}$ and $39.4 \%$ in $\mathrm{BS}$ in cases of extreme difficulty (CE score = 5), which were more than 10 times as likely to result in a stillborn calf. The increasing trend of \% SB in JE was consistent with BS and $\mathrm{HO}$ from $3.3 \%$ in the case of no difficulty to $16.7 \%$ in the case of needed assistance (CE score $=3$ ), but was constant afterward. The reason for that difference may be that JE calves are smaller than HO (Olson et al., 2009), and lower birth weights corresponded to less dystocia and fewer SB (Johanson and Berger, 2003; Berry et al., 2007). Increased \%SB were observed in all breeds as calving difficulty increased (Table 1), which was consistent with the results of Cole et al. (2007a) and Johanson and Berger (2003).

Phenotypic \%SB was $3.7 \%$ in $\mathrm{JE}, 5.1 \%$ in BS, and $6.3 \%$ in $\mathrm{HO}$ across all lactations. The distributions of \%SB by parity-sex combination of calves in all breeds are presented in Table 1. In the first parity, compared with purebred $\mathrm{HO}$ calvings, \% $\mathrm{SB}$ of purebred $\mathrm{BS}$

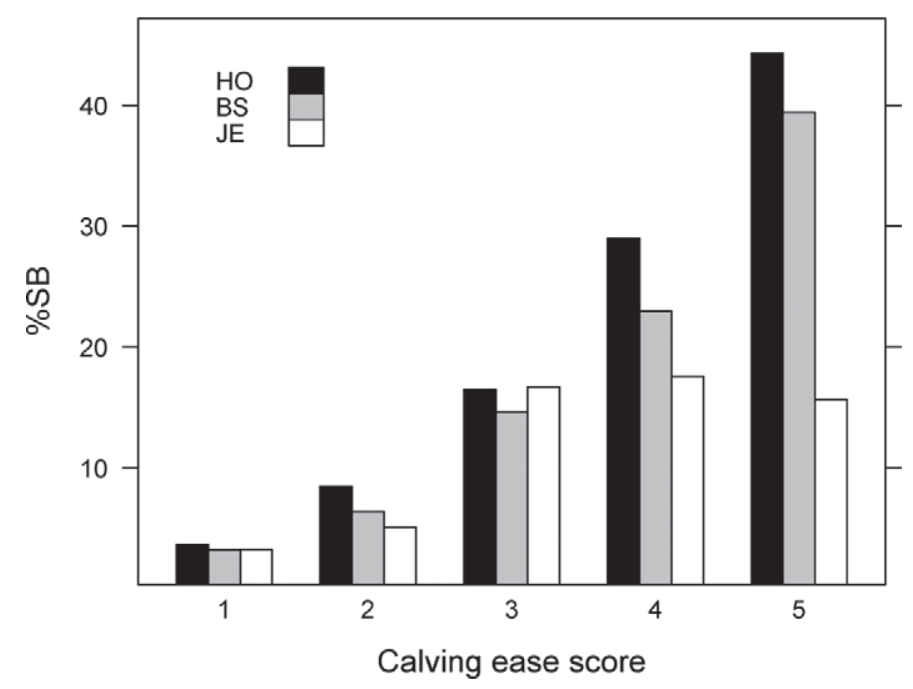

Figure 2. The average population percentage of stillbirth (\%SB) by calving ease score in Brown Swiss purebred and crossbred calvings (BS; gray bar), Jersey purebred and crossbred calvings (JE; white bar), and Holstein purebred calvings (HO; black bar). Calving ease scores: $1=$ no problem, $2=$ slight problem, $3=$ needed assistance, 4 $=$ considerable force, and $5=$ extreme difficulty. 
and JE calvings were lower by up to 5.5 and $7.8 \%$, respectively, and $\mathrm{BS} \times \mathrm{HO}$ and $\mathrm{JE} \times \mathrm{HO}$ crossbred calvings decreased \% $\mathrm{SB}$ by up to 3.8 and $4.1 \%$, respectively. These differences in later parities decreased to around 1\%, except JE purebred calvings with male calves. Results from a survey by Weigel and Barlass (2003) also indicated decreased \%SB when mating BS and JE bulls with $\mathrm{HO}$ cows, but higher \% $\mathrm{SB}$ in JE purebred calvings than HO. Stillbirth rates were the highest in primiparous cows regardless of calf sex, and were lower in later parities. These values are slightly higher than the overall rate of $7.9 \%$ SB in first-parity Danish HO (Hansen et al., 2004), and 7.1 and $2.7 \%$ for first- and second-parity cows of Swedish HO (Steinbock et al., 2003). The definition of SB used in those studies included mortality at birth and death within $24 \mathrm{~h}$, a shorter period than the $48 \mathrm{~h}$ definition used in the United States, which may explain part of the difference. The reductions in SB from primiparous to multiparous dams were also observed by Adamec et al. (2006) and Heins et al. (2006).

Distributions of \% SB with male and female calves in BS and JE differed from that of HO. Holstein male calves had higher \%SB than female calves by $2.8,0.8$, and $0.4 \%$ in first, second, and third-or-later parities, respectively, which was close to that in previous studies (Meyer et al., 2001b; Johanson and Berger, 2003; Cole et al., 2005; Heins et al., 2006; Maltecca et al., 2006; Berry et al., 2007; Dhakal et al., 2013). Stillbirth rates of female calves in JE purebred calvings, however, were higher than male calves by $0.3 \%$ (first parity), $1.2 \%$ (second parity), and 1.5\% (third-or-later parities). Female calves from BS purebred calvings had a higher SB rate in all later parities after the first, with differences of $-0.9,0.3$, and $0.6 \%$ in the first, second, and third-orlater parities, respectively. Higher \% SB in female calves was also reported in an early study of crossbred HO and Guernseys (Touchberry, 1992). The larger number of female calves than male calves in the first parity may be associated with the large amount of sexed semen used for nulliparous heifers (Norman et al., 2010).

Phenotypic trends (Supplementary Figure S1, available online at http://dx.doi.org/10.3168/jds.2013-7320) showed that \%SB decreased from 1999 to 2009 in all breeds. In primiparous cows, \% $\mathrm{SB}$ in $\mathrm{BS}, \mathrm{JE}$, and $\mathrm{HO}$ decreased from $7.3,7.1$, and $11.0 \%$ in $\leq 1999$ to $5.4,4.7$, and $9.2 \%$ in $\geq 2009$. Multiparous cows showed similar decreasing trends over the period in $\mathrm{BS}$ and $\mathrm{HO}$, whereas JE cows had a sharper downward trend after 2004. Primiparous cows presented more conspicuous year-toyear variation than cows. The differences among breeds were larger in primiparous cows than multiparous cows, which may be associated with larger differences in calving difficulty among breeds in primiparous cows than 
that in multiparous cows (Cole et al., 2005), as well as differences in time required to reach mature size.

Genetic trends for sire and maternal effects are presented in Figure 3 for bulls born since 1980. The numbers of BS, JE, and $\mathrm{HO}$ sires that received evaluations were $1,189,3,380$, and 56,912, respectively. The average DSB PTA has been decreasing since 1980 for all 3 breeds. The average SSB showed a slightly increasing trend in all 3 breeds from 1980 to the early 2000s, and $\mathrm{BS}$ and $\mathrm{HO}$ sires presented a decreasing trend after that. The genetic correlations between $\mathrm{SB}$ and $\mathrm{CE}$ were reported to be high in HO (Luo et al., 1999; Steinbock et al., 2003; Cole et al., 2007b). As a result, SB in the United States may have benefited from selection for CE since the 1980s (Berger, 1994; Van Tassell et al., 2003). Undesirable (increasing) phenotypic and genetic trends were observed for SB in Danish HO previously (Hansen et al., 2004), but favorable (decreasing) trends were observed in the current study.

Genetically, both BS and JE breeds had advantages over $\mathrm{HO}$ in \% $\mathrm{SB}$, and calves born from crossbred calvings benefited from the heterosis, which further reduces $\% \mathrm{SB}$. The breed composition solutions for HO purebred

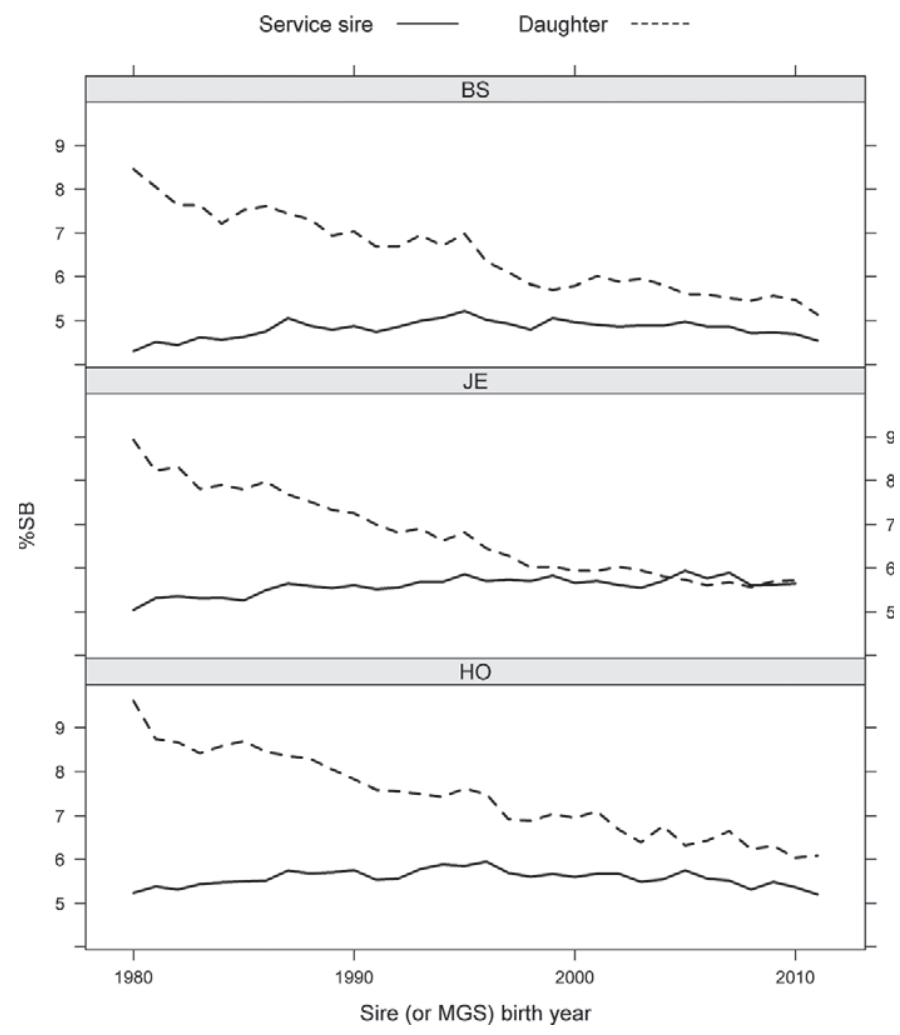

Figure 3. Mean service-sire (solid line) and daughter (dashed line) PTA for the percentage of stillbirths (\%SB) by sire or maternal grandsire (MGS) birth year of bulls born since 1980. BS = Brown Swiss; JE $=$ Jersey; $\mathrm{HO}=$ Holstein. calvings, BS purebred calvings, $\mathrm{BS} \times \mathrm{HO}$ crossbred calvings, JE purebred calvings, and $\mathrm{JE} \times \mathrm{HO}$ crossbred calvings were $-0.294,-0.396,-0.371,-0.328$, and -0.460 , respectively. The heterosis for $\mathrm{BS} \times \mathrm{HO}$ crossbred calvings was $(-0.371)-(-0.294-0.396) / 2$ $=-0.026$ on the underlying scale. Transformed to the observed scale on HO basis, the heterosis equaled approximately $-0.3 \%$ for SSB and $-0.5 \%$ for DSB. The heterosis for $\mathrm{JE} \times \mathrm{HO}$ crossbred calvings was $(-0.460)$ $-(-0.294-0.328) / 2=-0.149$ on the underlying scale, corresponding to $-1.5 \%$ for SSB and $-2.7 \%$ for DSB on the observed scale. Maternal heterosis was previously found to be significant in crossbreeding between HO and JE in primiparous cows (Dhakal et al., 2013). The BS and JE bulls had more desirable breed average \% SB compared with HO, and JE had greater heterosis with HO than BS.

Distributions of SSB and DSB PTA are shown in Figure 4. In contrast to the phenotypic means, BS had the most desirable average SSB PTA of $4.8 \%$, compared with $5.6 \%$ for JE and $5.5 \%$ for HO. This relationship also held on the underlying scale, where BS had the most negative average SSB $(-1.66)$, followed by HO (-1.60) and JE (-1.59). Brown Swiss and JE had very similar distributions of DSB, both averaging $6.5 \%$ $(-1.52)$ on the observed (underlying) scale, whereas HO averaged $7.7 \%(-1.43)$. Figure 1 shows that a large number of records with low \%SB in JE had been reported recently since 2007, and this had very limited effect on PTA means of JE bulls. Therefore, the genetic advantage of current JE bulls was not as large as JE phenotypic population \% SB relative to other breeds.

Reliabilities of SSB and DSB PTA for each breed are plotted in Supplementary Figure S2 (available online at http://dx.doi.org/10.3168/jds.2013-7320). The average reliabilities of SSB (DSB) PTA for BS, JE, and HO were 49 (50), 45 (45), and $47 \%$ (48\%), respectively. The number of bulls with reliability $\geq 90 \%$ for SSB (DSB) PTA for BS, JE, and HO were 46 (48), 88 (87), and 1,442 (1,660), respectively. More than $60 \%$ JE bulls had PTA with reliabilities less than $40 \%$, indicating that most JE bulls had very limited progeny information. For BS and HO, about 30 to $40 \%$ bull PTA had reliabilities less than $40 \%$. Compared with a previous SB evaluation in Cole et al. (2007a), the number of HO bulls for both SSB and DSB PTA with reliabilities below $40 \%$ decreased from about $45 \%$ to below $35 \%$, which indicated the value of reporting SB data to add usable records collected by the National Association of Animal Breeders (Columbia, MO). The larger number of records resulted in higher reliabilities for bulls.

Holstein PTA and reliabilities from the multibreed model were compared with the results from the April 2013 genetic evaluations to determine if the changes 


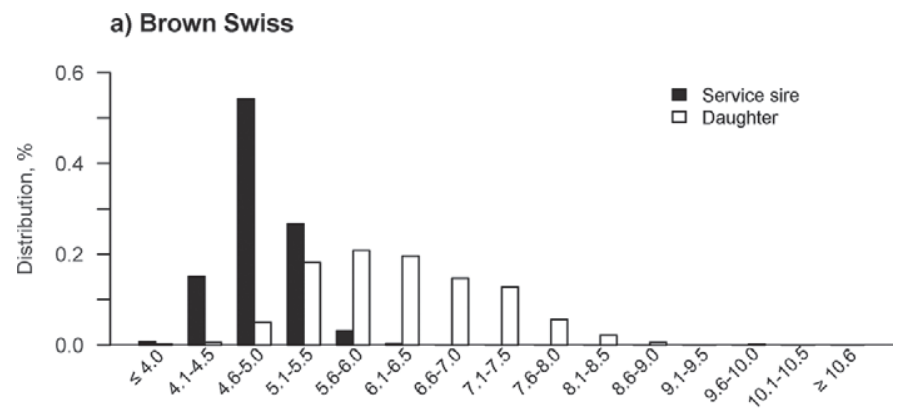

b) Jersey

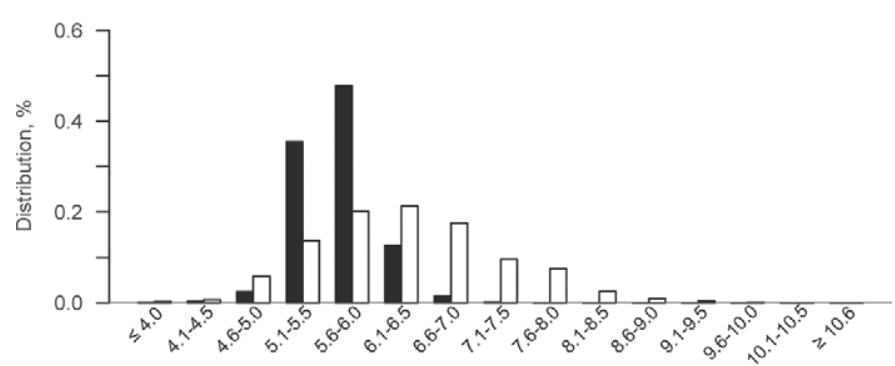

c) Holstein

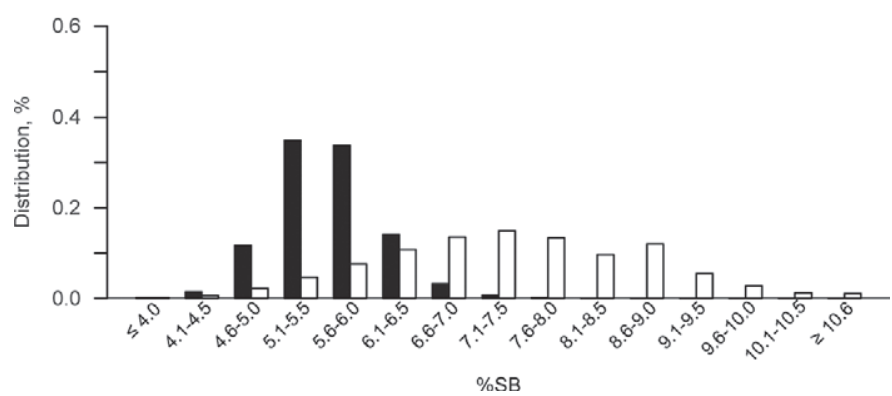

Figure 4. Distributions of service-sire (black bar) and daughter (white bar) PTA of the percentage of stillbirth (\%SB) for (a) Brown Swiss, (b) Jersey, and (c) Holstein bulls born since 1980.

made in the model affected $\mathrm{HO}$ results. Between the 2 runs, correlations of SSB and DSB PTA were 0.989 and 0.997. Correlations of their reliabilities were both 0.999, but reliabilities of SSB and DSB from the multibreed model were higher by 9.1 and $7.8 \%$, on average. These reliabilities indicated that the $\mathrm{HO}$ evaluations benefitted from the addition of the BS and JE data in the multibreed model.

In conclusion, the BS-JE-HO multibreed genetic evaluation for SB in the United States was feasible, and sufficient number of records existed for BS and JE to provide informative joint evaluation with $\mathrm{HO}$. Both purebred BS and JE calvings and crossbred calvings between BS and JE sires with HO dams had lower \%SB phenotypic means than purebred $\mathrm{HO}$, in general, especially in the first parity. Distributions of SB rates of male and female calves in BS and JE breeds differed from that in HO. Favorable (decreasing) phenotypic and genetic trends in SB rate were found. Brown Swiss bulls had more desirable average SSB PTA than JE and HO bulls, and both BS and JE bulls had lower DSB PTA means compared with HO. The BS and JE bulls had more desirable breed average \% SB compared with $\mathrm{HO}$, and JE bulls had greater heterosis to decrease $\% \mathrm{SB}$ in calves than BS bulls when bred to HO dams.

\section{ACKNOWLEDGMENTS}

The assistance of Jay Megonigal and Daniel Null (both of the Animal Improvement Programs Laboratory, Agricultural Research Service, US Department of Agriculture, Beltsville, MD) with data extraction and preparation is gratefully noted. The BLUPF90 family of computer programs was provided by Ignacy Misztal and Shogo Tsuruta of the University of Georgia (Athens). The cooperation of the American Jersey Cattle Association (Reynoldsville, OH), Brown Swiss Association (Beloit, WI), and Holstein Association USA (Brattleboro, VT) in supplying pedigree data for registered cows and the dairy records processing centers [AgriTech Analytics (Visalia, CA), AgSource Cooperative Services (Verona, WI), Dairy Records Management Systems (Raleigh, NC, and Ames, IA), and DHI Computing Services (Provo, UT)] in supplying pedigree data for grade cows and calving event data is acknowledged. The National Association of Animal Breeders (Columbia, MO) contributed to funding the national calving traits evaluations and this research project. Cole was supported by appropriated project 1265-31000-096-00, "Improving Genetic Predictions in Dairy Animals Using Phenotypic and Genomic Information." Support for Yao was provided by Hatch grant \#WIS01595 from the Wisconsin Agricultural Experiment Station and the National Association of Animal Breeders (Columbia, MO). The authors appreciate the input of two anonymous peer reviewers, whose advice greatly improved the manuscript.

\section{REFERENCES}

Adamec, V., B. G. Cassell, E. P. Smith, and R. E. Pearson. 2006. Effects of inbreeding in the dam on dystocia and stillbirths in US Holsteins. J. Dairy Sci. 89:307-314.

Berger, P. J. 1994. Genetic prediction for calving ease in the United States: Data, models, and use by the dairy industry. J. Dairy Sci. 77:1146-1153.

Berry, D. P., J. M. Lee, K. A. Macdonald, and J. R. Roche. 2007. Body condition score and body weight effects on dystocia and stillbirths and consequent effects on postcalving performance. J. Dairy Sci. 90:4201-4211.

Bicalho, R. C., K. N. Galvão, S. H. Cheong, R. O. Gilbert, L. D. Warnick, and C. L. Guard. 2007. Effect of stillbirths on dam survival and reproduction performance in Holstein dairy cows. J. Dairy Sci. 90:2797-2803.

Bicalho, R. C., K. N. Galvão, L. D. Warnick, and C. L. Guard. 2008. Stillbirth parturition reduces milk production in Holstein cows. Prev. Vet. Med. 84:112-120. 
Cole, J. B., R. C. Goodling Jr., G. R. Wiggans, and P. M. VanRaden. 2005. Genetic evaluation of calving ease for Brown Swiss and Jersey bulls from purebred and crossbred calvings. J. Dairy Sci. $88: 1529-1539$.

Cole, J. B., P. M. VanRaden, and Multi-State Project S-1040. 2009 AIPL Research Report NM\$4: Net merit as a measure of lifetime profit: 2010 revision. Accessed July 16, 2013. http://aipl.arsusda. gov/reference/nmcalc-2010.htm.

Cole, J. B., G. R. Wiggans, and P. M. VanRaden. 2007a. Genetic evaluation of stillbirth in United States Holsteins using a sirematernal grandsire threshold model. J. Dairy Sci. 90:2480-2488.

Cole, J. B., G. R. Wiggans, P. M. VanRaden, and R. H. Miller. 2007b. Stillbirth (co)variance components for a sire-maternal grandsire threshold model and development of a calving ability index for sire selection. J. Dairy Sci. 90:2489-2496.

Dhakal, K., C. Maltecca, J. P. Cassady, G. Baloche, C. M. Williams, and S. P. Washburn. 2013. Calf birth weight, gestation length, calving ease, and neonatal calf mortality in Holstein, Jersey, and crossbred cows in a pasture system. J. Dairy Sci. 96:690-698.

Eaglen, S. A. E., M. P. Coffey, J. A. Woolliams, and E. Wall. 2012 Evaluating alternate models to estimate genetic parameters of calving traits in United Kingdom Holstein-Friesian dairy cattle. Genet. Sel. Evol. 44:23.

Fuerst, C., and C. Egger-Danner. 2003. Multivariate genetic evaluation for calving ease and stillbirth in Austria and Germany. Interbull Bull. 31:47-51.

Hansen, M., I. Misztal, M. S. Lund, J. Pedersen, and L. G. Christensen. 2004. Undesired phenotypic and genetic trend for stillbirth in Danish Holsteins. J. Dairy Sci. 87:1477-1486.

Heins, B. J., L. B. Hansen, and A. J. Seykora. 2006. Calving difficulty and stillbirths of pure Holsteins versus crossbreds of Holstein with Normande, Montbeliarde, and Scandinavian Red. J. Dairy Sci. $89: 2805-2810$.

Jakobsen, J. H., and F. Fikse. 2005. Feasibility of MACE for calving traits for non-Holstein breeds. Interbull Bull. 33:28-33.

Johanson, J. M., and P. J. Berger. 2003. Birth weight as a predictor of calving ease and perinatal mortality in Holstein cattle. J. Dairy Sci. $86: 3745-3755$

Johanson, J. M., P. J. Berger, S. Tsuruta, and I. Misztal. 2011. A Bayesian threshold-linear model evaluation of perinatal mortality, dystocia, birth weight, and gestation length in a Holstein herd. J. Dairy Sci. 94:450-460.

Luo, M. F., P. J. Boettcher, J. C. M. Dekkers, and L. R. Schaeffer 1999. Bayesian analysis for estimation of genetic parameters of calving ease and stillbirth for Canadian Holsteins. J. Dairy Sci. 82:1848.e1-1848.e11.

Maltecca, C., H. Khatib, V. R. Schutzkus, P. C. Hoffman, and K. A. Weigel. 2006. Changes in conception rate, calving performance, and calf health and survival from the use of crossbred Jersey $\times$ Holstein sires as mates for Holstein dams. J. Dairy Sci. $89: 2747-2754$

Meyer, C. L., P. J. Berger, K. J. Koehler, J. R. Thompson, and C G. Sattler. 2001a. Phenotypic trends in incidence of stillbirth for Holsteins in the United States. J. Dairy Sci. 84:515-523.

Meyer, C. L., P. J. Berger, J. R. Thompson, and C. G. Sattler. 2001b. Genetic evaluation of Holstein sires and maternal grandsires in the United States for perinatal survival. J. Dairy Sci. 84:1246-1254.

Misztal, I., S. Tsuruta, T. Strabel, B. Auvray, T. Druet, and D. H. Lee. 2002. BLUPF90 and related programs. Commun. No. 28-07 in Proc. 7th World Congr. Genet. Appl. Livest. Prod., Montpellier, France.

Norman, H. D., J. L. Hutchison, and R. H. Miller. 2010. Use of sexed semen and its effect on conception rate, calf sex, dystocia, and stillbirth of Holsteins in the United States. J. Dairy Sci. 93:38803890

Olson, K. M., B. G. Cassell, A. J. McAllister, and S. P. Washburn. 2009. Dystocia, stillbirth, gestation length, and birth weight in Holstein, Jersey, and reciprocal crosses from a planned experiment. J. Dairy Sci. 92:6167-6175.

R Core Team. 2013. R: A language and environment for statistical computing. R Foundation for Statistical Computing, Vienna, Austria.

Sarkar, D. 2008. Lattice: Multivariate Data Visualization with R Springer, New York, NY.

Steinbock, L., A. Näsholm, B. Berglund, K. Johansson, and J. Philipsson. 2003. Genetic effects on stillbirth and calving difficulty in Swedish Holsteins at first and second calving. J. Dairy Sci. $86: 2228-2235$

Touchberry, R. W. 1992. Crossbreeding effects in dairy cattle: The Illinois experiment, 1949 to 1969. J. Dairy Sci. 75:640-667.

Van Tassell, C. P., G. R. Wiggans, and I. Misztal. 2003. Implementation of a sire-maternal grandsire model for evaluation of calving ease in the United States. J. Dairy Sci. 86:3366-3373.

Weigel, K. A., and K. A. Barlass. 2003. Results of a producer survey regarding crossbreeding on US dairy farms. J. Dairy Sci. $86: 4148-4154$ 